\title{
Deaths Exceeded Births in a Record Number of States in 2020
}

Kenneth M. Johnson

In 2020, the impact of COVID-19 contributed to a record 3,376,000 deaths in the United States: 18 percent more than in 2019. In addition, births diminished by 4 percent to 3,605,000 in 2020. Because U.S. population growth depends on a surplus of births over deaths, this slowed U.S. population growth in 2020. The surplus of births over deaths added just 229,000 to the population in 2020 compared to 892,000 in 2019: a decline of 74 percent. This decline coupled with diminished immigration produced the United States' smallest annual percentage population gain in at least 100 years.

These losses were felt across the United States as deaths increased significantly and births modestly diminished in every state. As a result, more people died than were born in 25 states in 2020, far exceeding the 2019 record of 5 states with more deaths than births. In 2020, 20 states had more deaths than births for the first time in history. All 5 of the states that had more deaths than births in 2019 did so again in 2020. Fertility declined sharply in late 2020 because women delayed pregnancies as the pandemic spread. In December 2020, roughly 9 months after the onset of the pandemic, there were 8 percent fewer births than in December 2019, and preliminary data suggest a similar reduction in January 2021. With births still declining and nearly 200,000 COVID-19 deaths already this year, deaths will likely exceed births again in many states in 2021. How large or protracted these fertility declines and mortality increases will be remains to be seen, but they have already dramatically reduced population growth in the United States.

\section{STATES WHERE DEATHS EXCEEDED BIRTHS, 2019 AND 2020}

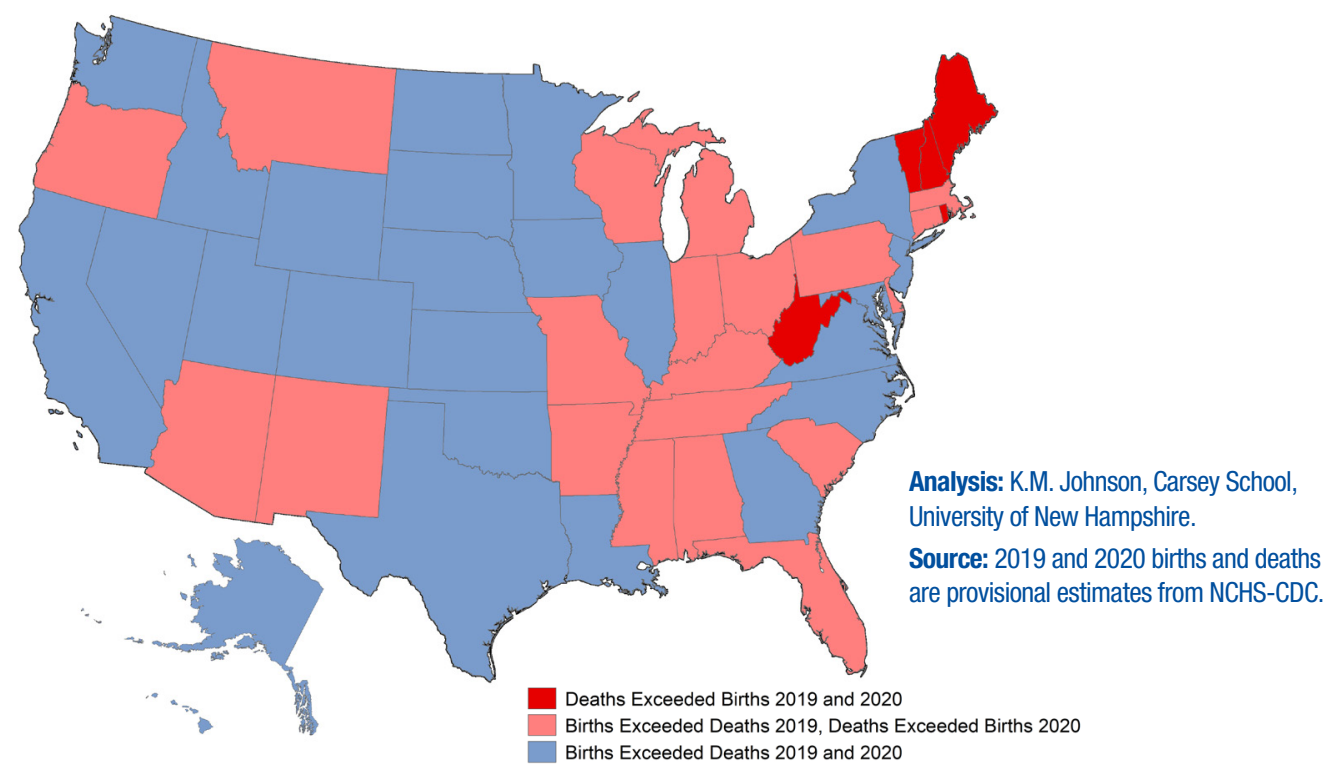

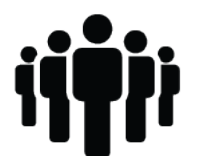

Many more deaths, fewer births, and less immigration produced the United States' smallest percentage population gain in at least $\mathbf{1 0 0}$ years.

See Related Publications at carsey.unh.edu

- 2020 Census Reflects Lagging U.S. Population Growth (April 2021)

- U.S. Fertility Rates and Births Continue to Diminish (May 2020)

\section{About the Author}

Kenneth M. Johnson is senior demographer at the Carsey School of Public Policy, professor of sociology at the University of New Hampshire, and an Andrew Carnegie Fellow. His research was supported by the New Hampshire Agricultural Experiment Station in support of Hatch MultiState Regional Project W-4001 through joint funding of the National Institute of Food and Agriculture, U.S. Department of Agriculture, under award number 1013434, and the state of New Hampshire. The opinions are his and not those of the sponsoring organizations. Research assistance by Kristine Bundschuh and map by Barbara Cook. 